\section{Hito y Retroceso en la Violencia Racial bajo el Sistema Europeo de Derechos Humanos: El Caso Nachova y Otros v. Bulgaria}

Patricia Palacios Zuloaga*
En julio de 2005 la Gran Cámara de la Corte Europea de Derechos Humanos ("la Corte") dictó sentencia en el caso Nachova y Otros v. Bulgaria ${ }^{1}$, poniendo fin a la polémica en torno a cuál debe ser la postura de los Estados Partes, y de la misma Corte, al verse enfrentados con posibles casos de violencia racial. El caso había sido resuelto con anterioridad por la Cámara de la misma Corte en febrero de 2004, siendo posteriormente elevado al conocimiento de la Gran Cámara a solicitud del Estado.

Los hechos que motivaron la comunicación internacional ocurrieron nueve años antes de la sentencia final, en julio de 1996, en la localidad de Lesura, Bulgaria. Las víctimas, el señor Angelov y el señor Petkov, ambos militares conscriptos de origen Roma ${ }^{2}$, cumplían condena por repetidas ausencias de su regimiento y, al ser llevados fuera de la prisión a trabajar, huyeron a Lesura, donde residía la abuela del señor Angelov. Cuatro días después de la fuga de las víctimas y luego de recibir un Ilamado telefónico anónimo que indicaba su paradero, efectivos de la policía militar fueron enviados a detenerlos, debiendo para ello usar "cualquier medio dictado por las circunstancias" ${ }^{3}$. Ninguna de las víctimas tenía antecedentes de violencia, asimismo, ninguno portaba armas al momento de los hechos materia del caso. Al llegar el grupo de cuatro policías militares al domicilio donde se escondían las víctimas, éstos huyeron por una ventana trasera siendo perseguidos por el oficial encargado del operativo, el mayor G. Luego de gritar advertencias y de disparar al aire, y al ver que el señor Angelov y el señor Petkov no se detenían, el mayor G. procedió a dispararles con su rifle automático, hiriendo de muerte a ambos. De acuerdo con el testimonio de un vecino que presenció los hechos, y que también era de origen Roma, luego de ocurrido lo anterior el mayor G. lo apuntó con su arma y le dijo: "¡Malditos gitanos!"4

Las autopsias practicadas en los cadáveres de las víctimas indicaron que, mientras que el señor Angelov murió a causa de un disparo que recibió estando con su espalda hacia el tirador, el señor Petkov murió por una herida de bala en el pecho, hecho que en palabras de la Corte plantea la "posibilidad de que el señor Petkov volteó para rendirse a última hora, pero que, no obstante, igualmente fue baleado ${ }^{5}$ ".

Esta posibilidad nunca fue comprobada, pues la investigación que llevaron a cabo las autoridades militares correspondientes fue completamente
* Abogada, Investigadora del Centro de Derechos Humanos, Facultad de Derecho, Universidad de Chile.

1 Corte Europea de Derechos Humanos, Caso Nachova and Others v. Bulgaria, Applications $\mathrm{N}^{\text {os }}$ 43577/98 and 43579/ 98 , sentencia de la Gran Cámara del 6 de julio de 2005.

2 El término "origen Roma" se usa para referirse a personas que solían ser denominados con el término peyorativo "gitanos".

3 Corte Europea de Derechos Humanos, op. cit., nota 2, párrafo 19, traducción propia.

4 Ibídem, párrafos 20 a 35 , traducción propia. Resulta importante notar que todos los integrantes del equipo de policía militar fueron instruidos para usar chalecos antibalas y a portar tanto pistolas como rifles automáticos para este operativo. Sin embargo, sólo el mayor G., autor de los disparos, usó chaleco

Este comentario, junto con el documento principal a que se refiere, están disponibles en www.anuariocdh.uchile.cl 
antibalas y sólo él, además de llevar su pistola, sacó su rifle automático del jeep en que llegaron.

5 Ibídem, párr. 108 (iii), traducción propia.

6 Ibídem, párr. 51. Su informe describe a las víctimas como provenientes de "familias minoritarias", un término usado para referirse a familias de origen Roma. Ibídem, párr. 52.

7 Ibídem, párr. 53, traducción propia.

8 Corte Europea de Derechos Humanos, Caso Nachova and Others v. Bulgaria, Applications $\mathrm{N}^{\text {os }} 43577 / 98$ y 43579/98, sentencia de la Cámara de 26 de febrero de 2004. El artículo 2 del Convenio Europeo contiene el derecho a la vida, mientras que el artículo 14 del mismo instrumento contiene la cláusula de no discriminación. En el Sistema Europeo de Derechos Humanos, a diferencia del Sistema Interamericano, la jurisprudencia postula que cada derecho enunciado en el Convenio Europeo comprende tanto un aspecto sustantivo como procedimental. En términos sencillos, el aspecto sustantivo hace referencia a la acción u omisión que da lugar a la afectación del derecho mientras que el aspecto procedimental dice relación con la obligación posterior del Estado de investigar el hecho y sancionar a los responsables.

9 Corte Europea de Derechos Humanos, op. cit., nota 2, párrs. 99 y 100, traducción propia. deficiente, basándose mayormente en el testimonio de los efectivos militares involucrados. La apelación de la resolución del fiscal militar que cerró la investigación ${ }^{6}$, interpuesta por las familias de las víctimas, fue rechazada, pues según la autoridad militar correspondiente las víctimas "provocaron el tiroteo al intentar huir y [...] el mayor G. actuó de acuerdo con los requerimientos de la ley para tales situaciones" ${ }^{\prime 7}$. La Cámara de la Corte Europea no estuvo de acuerdo, encontrando, en febrero de 2004, violaciones sustantivas y procedimentales tanto del artículo 2 leído aisladamente como del artículo 14 leído conjuntamente con el $2^{8}$. Como ya se ha mencionado, el Estado búlgaro solicitó la revisión de esta sentencia por la Gran Cámara de la misma Corte.

El examen de este caso ante la Gran Cámara plantea a lo menos tres temas de interés para el Derecho Internacional de los Derechos Humanos. En primer lugar, qué se debe entender por exceso de fuerza. Al encontrar violado el aspecto sustantivo del derecho a la vida de las víctimas, la Corte hizo referencia al ordenamiento jurídico interno "fundamentalmente deficiente", que permite el baleo de cualquier fugitivo que no se rinde inmediatamente después de una advertencia oral y un disparo al aire ${ }^{9}$. La Corte recordó su jurisprudencia anterior al afirmar que:

“...[E]l fin legítimo de detener a una persona en cumplimiento de la ley sólo puede justificadamente poner en peligro la vida humana en casos de necesidad absoluta [...N] o existe dicha necesidad cuando se sabe que la persona que será detenida no representa peligro para la vida o la integridad y cuando no se sospecha que ha cometido un delito violento, aun cuando la ausencia de fuerza letal pueda resultar en la pérdida de la oportunidad de efectuar la detención del fugitivo ${ }^{10 "}$.

Por otro lado, la Corte también se refirió a la planificación del operativo como demostrativo de una "deplorable falta de respeto por la preeminencia del derecho a la vida" y a la "fuerza groseramente excesiva" usada por el mayor G. para finalmente encontrar responsable al Estado búlgaro por la violación del aspecto sustantivo del artículo $2^{11}$.

En segundo lugar, el fallo también continúa la línea jurisprudencial de la Corte en cuanto a la exigencia de una investigación efectiva de posibles violaciones de derechos humanos. En este sentido, la Corte estimó que las graves falencias en la investigación de los hechos materia del caso hacían responsable al Estado de una violación del aspecto procedimental del derecho a la vida de las víctimas, encontrando de esta manera una segunda violación del artículo 2 del Convenio ${ }^{12}$.

En tercer lugar, este caso plantea el problema de la violencia motivada por prejuicios raciales. La posibilidad de que Angelov y Petkov pudieron haber sido asesinados porque eran étnicamente Roma fue el aspecto más polémico de la vista del caso ante ambas cámaras de la Corte ${ }^{13}$.

Para entender el razonamiento de la Corte en esta materia, es preciso dejar en claro que el artículo 14 del Convenio Europeo, que contiene la prohibición de discriminación, es una cláusula subordinada, vale decir, 
no puede ser violado autónomamente, sino que debe ser invocado en conjunto con un derecho reconocido en el Convenio y sus protocolos ${ }^{14}$. Así, en el presente caso los peticionarios alegaron que el Estado búlgaro violó el aspecto sustantivo del artículo 14 en conjunto con el artículo 2 por cuanto los asesinatos fueron motivados racialmente. Asimismo, alegaron una violación del aspecto procedimental del artículo 14 juncto 2 por cuanto no hubo una investigación diligente de la posibilidad de que los asesinatos fueron un acto de violencia racial.

A diferencia de otros órganos de control internacional, la Corte Europea no ha sido propensa a encontrar violaciones del artículo 14, prefiriendo muchas veces encontrar sólo violaciones del derecho principal alegado ${ }^{15}$. Además, antes de la sentencia de la Cámara en el caso Nachova, la Corte nunca había encontrado que un Estado había violado el artículo 14 por haber incurrido en una discriminación racial.

Lo anterior puede deberse a que, antes de Nachova, la regla general (aunque no absoluta) aplicada por la Corte era aquella que exigía a los peticionarios "prueba más allá de la duda razonable"16. Esto hacía que en la práctica resultara difícil que un peticionario lograra probar la existencia de la discriminación en casos particulares. La Corte Interamericana de Derechos Humanos y el Comité de Derechos Humanos de Naciones Unidas se han aproximado al problema de la carga de la prueba en el examen de comunicaciones individuales de otra manera: la Corte Interamericana ha sostenido que, ante la negativa del Estado a investigar los hechos y a ofrecer una explicación plausible por lo ocurrido, se puede tener por probado lo afirmado por el peticionario ${ }^{17}$. Más específicamente en materia de discriminación, el Comité de Derechos Humanos ha sostenido que corresponde al peticionario probar que existió tratamiento desigual, mientras que al Estado le corresponde demostrar que dicho tratamiento desigual obedece a criterios objetivos y razonables ${ }^{18}$. Ante un caso como el que estamos analizando, en donde no ha habido investigación diligente y en donde los peticionarios carecen del poder necesario para recopilar pruebas, me parece más apropiada la aproximación de la Corte Interamericana y del Comité para no colocar a los peticionarios en una posición desde donde les es imposible probar sus pretensiones.

La primera sentencia de la Corte en el caso Nachova, adoptada por la Cámara, parece recoger el razonamiento anterior al deducir una violación sustantiva del artículo 14 juncto 2 a partir de la falta de investigación de la posible motivación racial de los asesinatos, vale decir, a partir de la violación procedimental del artículo 14 juncto $2^{19}$. Estableció que:

"La Corte considera que al investigar incidentes de violencia, particularmente muertes a manos de agentes estatales, las autoridades estatales tienen el deber adicional de tomar todas las medidas razonables para descubrir cualquier motivación racista y para establecer si es que el odio o prejuicio étnico pudieron haber influido en los hechos. No hacer esto y tratar la violencia y brutalidad racial de igual manera que casos sin motivación racista sería cegarse ante la naturaleza específica de hechos
10 Ibídem, párr. 95, traducción propia.

11 Ibídem, párr. 105 y 108.

12 Ibídem, párr. 119.

13 En su solicitud de revisión de la sentencia de la Cámara por la Gran Cámara, el Estado reconoció la violación del derecho a la vida de las víctimas, sin embargo, impugnó que los asesinatos se produjeran por la raza de Angelov y Petkov. Ibídem, párr. 83. Véase, además, el resumen de los escritos de Amicus Curiae recibidos por la Gran Cámara en ibídem, párrs. 138143.

14 Bayefsky, Anne, "The Principle of Equality or Non-discrimination in International Law", reproducido en el compilado International Human Rights Law, Volumen II, ed. profesora Rebecca J. Cook, Facultad de Derecho, Universidad de Toronto 1991-92, p. 66. Además, Corte Europea de Derechos Humanos, Caso "Relating to Certain Aspects of the Law on the Use of Languages in Education in Belgium", sentencia del 23 de julio de 1968. Examen de fondo.

15 Ver, por ejemplo, los casos emblemáticos de la Corte Europea, Airey v. Irlanda de octubre de 1979 y Dudgeon v. el Reino Unido de octubre de 1981 en donde la discriminación por sexo y orientación sexual respectivamente fueron hechos claves $y$ en donde no se encontró violación del artículo 14. La Corte prefirió resolver estos 
casos en base al derecho al debido proceso y a la intimidad respectivamente.

16 La Cámara de la Corte, en su sentencia de 2004, deja en claro que este concepto no es asimilable al estándar requerido en causas criminales sino que se compone de "la coexistencia de inferencias suficientemente fuerte, claras y concordantes o de similares presunciones irrebatidas". Corte Europea de Derechos Humanos, op. cit., nota 8 , párr. 166 , traducción propia.

17 Corte Interamericana de Derechos Humanos, Caso Velásquez Rodríguez, sentencia de 29 de julio de 1988, párr. 135 y Caso Neira Alegría y Otros, sentencia de 19 de enero de 1995, párr. 65 (esté último referente a pruebas que "estuvieron a disposición del Gobierno o deberían haberlo estado si éste hubiera procedido con la necesaria diligencia"). Además, para la Comisión Interamericana de Derechos Humanos, véase el artículo 39 de su Reglamento.

18 Comité de Derechos Humanos, Kavanagh v. Ireland, CCPR/C/71/D/ 819/1998, dictamen del 4 de abril de 2001, párr. 10.3.

19 Corte Europea de Derechos Humanos, op. cit., nota 8 , párr. 175.

20 Ibídem, párr. 158, traducción propia.

21 Ibídem, párrs. 163 y 164, traducción propia. que son particularmente destructivos de los derechos fundamentales. No distinguir en el tratamiento de situaciones esencialmente diferentes puede constituir tratamiento injustificado que es irreconciliable con el artículo 14 del Convenio ${ }^{20 \prime \prime}$.

Más adelante sigue:

"[L]a Corte encuentra que las autoridades fallaron en su deber bajo el artículo 14 del Convenio, entendido en conjunto con el artículo 2, de tomar todas las medidas posibles para establecer si es que actitudes discriminatorias pudieron haber influido en los hechos [...] La Corte considera, además, que la falla de las autoridades internas en el cumplimiento de ese deber deberá incidir en su aproximación en el presente caso al examen del reclamo de una violación sustantiva del artículo $14^{\prime \prime 21}$.

De este modo, basándose en el comportamiento del mayor G., la falta de investigación por parte del Estado (particularmente en relación con la posible motivación racista de los asesinatos), el contexto general de discriminación de personas de origen Roma en Bulgaria, la existencia de casos anteriores en donde se reclamó por violencia racial en contra de personas Roma a manos de agentes estatales ${ }^{22}$ y ante la ausencia de una explicación satisfactoria de los hechos por parte del Estado, la Cámara encontró responsable al Estado por violación del aspecto sustantivo del artículo 14 juncto $2^{23}$, vale decir, encontró que Angelov y Petkov fueron asesinados, porque eran de origen Roma.

Más allá del caso mismo, la importancia de esta decisión reside en que, al examinar la posibilidad de discriminación racial, la Cámara encontró justificado en este caso alterar la carga de la prueba y de este modo estableció un precedente que facilitaría para peticionarios futuros la tramitación de reclamaciones por discriminación bajo el Convenio Europeo.

Sin embargo, la satisfacción de los grupos que abogan por los derechos de minorías raciales en Europa duró poco. Como se ha dicho, luego de la sentencia de la Cámara, el caso fue elevado al conocimiento de la Gran Cámara de la Corte, a solicitud del Estado. La sentencia de la Gran Cámara confirmó lo concluido por la Cámara en cuanto a las violaciones tanto sustantiva como procedimental del artículo 2 y de la violación procedimental del artículo 14 juncto 2. Sin embargo, por once votos contra seis, encontró que no hubo prueba suficiente de una violación sustantiva del artículo 14 juncto 2. En términos sencillos, anuló el traspaso de la carga de la prueba efectuado por la Cámara y de esta manera sostuvo que los peticionarios no lograron probar "más allá de la duda razonable" que los asesinatos de Angelov y Petkov fueron motivados por el odio racial. Al hacer esto, parece que la Corte no comprendió que no alterar la carga de la prueba obliga a los familiares de las víctimas a probar la motivación racista del mayor G., cosa que resulta prácticamente imposible para personas individuales, en especial, donde no hubo investigación estatal y más aún tratándose de personas 
estructuralmente discriminadas como son los integrantes de las comunidades Roma en Bulgaria. Aunque la Corte reconoció su facultad de redistribuir la carga de la prueba, estimó que no procedía en este caso, pues "tal aproximación traería como resultado la necesidad que el Gobierno demandado probara la ausencia de una actitud subjetiva particular por parte de la persona en cuestión" 24 . En mi opinión, esto es ciertamente la consecuencia de alterar la carga de la prueba. Hay que decir, sin embargo, que en este caso el Estado tuvo la oportunidad de no incurrir en responsabilidad internacional probando la ausencia de motivación racial por medio de una investigación efectiva y no lo hizo. No me parece apropiado, desde cualquier prisma de justicia, asignar los perjuicios resultantes de la negligencia grave del Estado a los peticionarios, en especial, cuando se corre el riesgo de sugerir que la responsabilidad internacional se elude a través de la falta de investigación.

En la aplicación del criterio "más allá de la duda razonable", la Gran Cámara volvió a examinar los hechos relevantes, sin embargo, no los examinó como un conjunto, sino hecho por hecho. De este modo concluyó, entre otras cosas, que "nada sugiere que el mayor G. no hubiera usado su arma en un barrio no habitado por Roma [...] no es posible especular acerca de si el origen Roma del señor Angelov y el señor Petkov tuvo incidencia alguna en la percepción de ellos que tuvieron los oficiales [...] la declaración ["malditos gitanos"] en sí misma no es fundamento suficiente para concluir que el Estado demandado es responsable de un asesinato racista" ${ }^{25}$. En este examen, no se hizo referencia alguna al hecho de que Petkov murió de una herida de bala en el pecho, circunstancia que, examinado en conjunto con los hechos que la Gran Cámara sí analizó, hace muy difícil desatender la posible presencia de discriminación racial en este caso.

Es lamentable que el tratamiento que la Gran Cámara le dio al aspecto racial de este caso no parezca proporcional a la gravedad de los hechos, en especial, considerando que la raza es reconocida como una categoría sospechosa internacional cuya invocación como fundamento de una distinción siempre requiere de mayor justificación por parte del Estado ${ }^{26}$.

Es posible que la Gran Cámara no haya querido tomar el paso hacia el reconocimiento de la violencia racial en la nueva, más ancha, Europa. Una condena de esa naturaleza podría ser desastrosa para el Estado Parte involucrado; ilustración de esto es la petición hecha por Bulgaria a la Gran Cámara en donde reconoce su conformidad con la condena por violar el derecho a la vida de Petkov y Angelov, pero solicita que se reconsidera el aspecto discriminatorio de las muertes.

Luego del estudio de este fallo de la Gran Cámara, lamentablemente sobra decir que el hecho de que en más de 50 años de funcionamiento del Sistema Europeo no se ha encontrado responsable a un Estado por un asesinato por motivos raciales no necesariamente significa que, en ese tiempo, no ha habido Estados Europeos responsables por dicho tipo de crímenes.
22 Corte Europea de Derechos Humanos, Caso Velikova v. Bulgaria, Application № 41488/98 y Anguelova v. Bulgaria, Appliation № 38361/ 97, citados ambos en ibídem, párr. 173.

${ }^{23}$ Corte Europea de Derechos Humanos, op. cit., nota 19.

${ }^{24}$ Corte Europea de Derechos Humanos, op. cit., nota 2, párr. 157, traducción propia.

25 Ibídem, párrs. 150-153, traducción propia.

26 Bayefsy, Anne, op. cit., nota 14, pp. 73-76. Además, Comisión Europea de Derechos Humanos, East African Asians v. the United Kingdom, Application № 4403/70, párr. 207. 
